\title{
Human-Induced Impacts on Land Surface Temperature Dynamics in Osogbo, Osun State, Nigeria
}

\author{
Ajih, Enenche Simon, \\ Strategic Space Application, \\ National Space Research and Development Agency, Abuja \\ Balogun, Bolarinwa Olutayo, \\ African Regional Centre for Space Science and Technology Education in \\ English, Obafemi Awolowo University Campus, Ile Ife, Osun State

\section{Ekwe, David Onu,} \\ Strategic Space Application, \\ National Space Research and Development Agency, Abuja
}

URL:http://dx.doi.org/10.19044/esj.2020.v16n9p274

\begin{abstract}
The main goal of this study is to evaluate the impacts of humaninduced activities on land surface temperature dynamics of Osogbo, in Osun State, Nigeria. Land surface temperature dynamics, land use land cover dynamics and the relationship between land surface temperature (LST) and land-use land-cover (LULC) were assessed using Landsat satellite data (ETM+ and OLI/TIRS) of Oshogbo, Osun State, Nigeria. The radiometrically corrected thermal infrared bands of the Landsat images of 2000 and 2018 were used to retrieve land surface temperature while the Maximum Likelihood algorithm in Erdas imagine 9.2 was used to generate a classified image for the two periods. Land surface temperature maps, land cover index maps and Normalized Differential Vegetation Index (NDVI)) were generated. Correlation analysis using Pearson's Product Moment Method was carried out between land surface temperature and normalized differential vegetation index (NDVI) data and the land cover index was digitized and overlaid on the LST map of 2018 to determine the association between them. The results revealed noticeable decrease in vegetated areas of Osogbo with an accompanying increase in land surface temperature from $28.045^{\circ} \mathrm{C}$ in 2000 to $29.200^{\circ} \mathrm{C}$ in 2018. Built-up increased within the same periods from 19 to $42 \%$, which could be attributed to anthropogenic activities. The land surface temperature distribution maps showed a more pronounced intensity in areas of significant human activities than in areas covered by vegetation and waterbody. The
\end{abstract}


correlation coefficient values of -0.54418 and -0.48513 observed in the land surface temperature and normalized differential vegetation index values for 2000 and 2018 respectively, indicated an inverse relationship between the two variables. The study concluded that the nature of land use / land cover patterns in Osogbo have impacted its land surface with a corresponding increase in land surface temperature. It is expected that as the city expands further, the magnitude of the land surface temperature will also increase thereby affecting the living conditions of the urban populace.

Keywords: Human impacts, Land surface temperature, Nigeria, land use/land cover, NDVI, Landsat images

\section{Introduction}

In recent times, there have been growing concerns on the possible impacts of human activities on the environment. This has resulted into the emergence of some nomenclatures like, climate change, global warming, earth drift, greenhouse effect, etc. Environmental analysts are of the views that these were caused largely by anthropogenic activities: combustion of fossil fuels and changes in land-use (Costello et al., 2009). All these activities have a direct impact on the near earth surface temperature. It has been stated that the global average combined land and ocean surface temperature data calculated by a linear trend show a warning of 0.85 (0.65 to 1.06$){ }^{\circ} \mathrm{C}$ between 1880 to 2012 while the global surface temperature has increased by $0.18^{\circ} \mathrm{C}$ during the last hundred years ending in 2005 and is expected to increase to $1.4^{\circ} \mathrm{C}$ by 2100 (IPCC, 2014). This is attributable to the onset of the industrial age, which culminated in increased urbanization which is expected to continue.

Increasing local ambient temperature implies higher human exposure to heat such that during hot seasons in hot regions of the world, people who are not able to afford either the cost of air conditioning and other cooling methods or the cost of energy required to run them, will be subjected to very severe heat stress and health risks. Both general living environments and working environments will be affected. The latter may impact workers' health, productivity, and socio-economic development (Bowen et al., 2012). Workers on low and middle income in tropical countries are likely to be at the highest risk of excessive heat exposure. Due to anthropogenic activities, the earth's surface is being significantly altered in some manner, and human presence on the earth and use of the land has had a profound effect on almost all meteorological/climate parameters. In order to make the environment more conducive, humans have built structures in urban areas to cater for their needs. These urban structures had been observed to alter the surface energy budget, modify the vertical profile of various atmospheric properties and interact with both local and regional circulation (Argüeso et al., 2015). 
Deforestation has resulted in habitat damage, biodiversity loss and aridity etc. As a result of human activities taking place on daily basis like roads, rails, houses, dams and oil exploration, most of all these falls into urbanization that contributes to deforestation process due to lack of proper reforestation planning that should have been going on simultaneously with this development (Emeodilichi, 2018). According to Daley (2018), the number one major problem caused by deforestation is the impact on the global carbon cycle. According to the 2010 global Forest Resource Assessment, deforestation due to human activities releases nearly a billion tons of carbon into the atmosphere per year. This carbon released causes climate change which creates severe weather conditions like drought, floods and hot weather conditions. According to Mfon et al., (2014) Nigeria has eight National Parks; of the entire eight and damages inflicted to these parks as a results of human and natural factors are tremendous and it will keep on increasing everyday if not properly addressed.

Urbanization is occurring in many countries, increasing the concentration of population in cities. There is a remarkable rate of urbanization in some developing countries over recent decades because of the pursuit of fast economic development (Zhou et al., 2004). Nigeria is not left out in this urbanization trend. This has resulted in the creation of big towns and cities. One of such towns is Osogbo, which has witnessed rapid development since its designation as the capital of Osun state in 1991. According to the 2006 population and Housing Commission Census, the city of Osogbo has a population of 156,694 people but in 2015 , the population of Osogbo was estimated to be 649,600, (Administrative Unit Osun). The rate of population growth has been spectacular in recent times. Compared to growth rate of 2.6 per cent annually for the total population, the urban population in Nigeria according to Alkali (2005), over the last three decades has been growing close to 5.4 per cent per annum. Rapid rural-urban migration and population growth in the cities over the past decades have led to an unprecedented rate of urbanization globally (Ayedun et al., 2011), and it is likely to continue in the subsequent decades (Cohen, 2006). A direct environmental consequence of population growth is the modification of land surfaces temperature which results in the alteration of its physical properties including soil moisture, material heat capacity, and surface reflectivity and emissivity. This leads to change in land surface temperature and the decrease in evapotranspiration (Chudnovsky et al., 2004).

The integration of remote sensing and Geographical Information System provides a powerful way to effectively monitor urban environment and human activities. Considerable researches have been demonstrated using remotely sensed information to detect thermal characteristics of urban surfaces (Weng, 2009; Kimuku and Ngigi 2017; Voogt and Oke 2003; Liu et al., 2011). 
The use of satellite infrared remote sensing in estimating the surface physical properties and variables has been investigated (Le Hung 2014; Dousset, et al., 2011; Georgescu et al.,2015; Owen et al., 1998; Quattrochi and Luvall, 2014; Dousset and Gourmelon, 2003). From these previous researches, UHI studies were performed using the in-situ measurements of air temperature in remote location away from human interference, but this method is not well suited to the analysis of the spatial distribution of temperatures. But using remote sensing technology, data with multi-temporal, multi-spectral and multiresolution characteristics are acquired. From this data the spatial distribution of temperature can then be determined. UHI affects the animal and plant lives in a variety of ways. This effect poses a great threat to human, animal and plant lives, such as the rising cost of air conditioners, physiological stress on animals, change in the mix of plants and animals that living in the area. Studies have shown that this can lead to changes in the distribution of vector-borne diseases (Lundgren-Kownacki et al., 2018).

\subsection{Statement of the Problem}

The rapid expansion of our cities and its attendant problems of urban sprawl, stresses on available infrastructure etc., leaves much to be desired. This phenomenon has resulted in deforestation, land reclamations in the coastal towns and conversion of agricultural land into settlements with permanent structures. This, no doubt, has altered the land surface temperature pattern due to human induced activities in the urban areas. A direct environmental consequence of this is the modification of land surfaces which results in the alteration of its physical properties including soil moisture, material heat capacity and surface reflectivity and emissivity. This leads to change in surface temperature and decrease in evapotranspiration. Studies have showed that prolong increase in Land Surface Temperature of any geographical location due to rapid growth in population results to heat wave (Streutker, 2002; Voogt et al., 2003) which can pose threat to the life of the residents and the local climate of that location.

In Osogbo, the capital city of Osun state and in neighbouring States such as Oyo, Lagos and Ekiti, deaths have occurred due to the meningitis epidemic associated with excessive heat; and inhabitants encountered other problems such as fatigue, headache, rashes, dehydration, and increased restlessness due to increased temperature (Nnadi et al., 2017; Dahl, 2013). To combat this issue, the inhabitants resorted to increased usage of airconditioning units and this has led to an increased power consumption, from approximately $74.13 \mathrm{KWh}$ in 2000 to $178.38 \mathrm{KWh}$ in 2013 (Auffhammer et al., 2017), an issue in this period of economic recession. Cities indirectly drive climate change through their enormous energy and consumption, material 
needs, waste and pollution production (Kershaw et al., 2010) and Osogbo as a major city in the tropics, has contributed to this phenomenon.

Goudie (1999) stressed that the most pronounced and locally far reaching effects of man's activities on microclimate have been in cities. For instance, Getis et al., (1987) discovered that smog is formed faster in cities because of the hot weather. Zhou et al (2004), generally find out that human induced changes in land-use such as urbanization among other factors affect both local and regional climate and even large scale atmospheric circulations. Therefore, studying the dynamics of this land surface temperature variable and decoding its relationship with the change that is taking place in our environment become the major focus of this study.

\subsection{Justification for the Study}

Surface temperature as an important factor in urban micro-climate is studied to provide quantitative information on the effects of the degree of surface sealing and vegetated surfaces for purpose of integrated urban planning. A careful study of the micro-climate will help our urban planners structure our cities in such a way that it will be habitable for man. Land surface temperature affects humans, animals, distribution of plant species and pathogens.

\subsection{Aim of this study}

The aim of this study is to evaluate the impacts of human-induced activities on land surface temperature dynamics of Osogbo, in Osun State.

\subsection{Objectives of the study}

The specific objectives of this study are to:

1. determine the trend in the land surface temperature in the study area between 2000 and 2018,

2. ascertain the human induced impacts on land surface temperature; and

3. evaluate the relationship between the rate of temperature change and human-induced-impacts in the study area.

\subsection{Study Area}

Osogbo is a city located between latitude $7^{\circ} 46^{\prime} 00^{\prime \prime}$ and $7^{\circ} 56^{\prime} 700^{\prime \prime} \mathrm{N}$ and longitude $4^{\circ} 34^{\prime} 00^{\prime \prime}$, and $4^{\circ} 56^{\prime} 00^{\prime \prime} \mathrm{E}$, in the south-western region of Nigeria. It is the capital city of Osun state with an estimated population of 819,800 and landmass of 140km (Adedotun, et al., 2016). The headquarters of both Osogbo and Olorunda local Government Areas are situated in the city. Osogbo shares boundary with Ikirun, Ilesa, Ede, Egbedore and Iragbiji and is easily accessible from any part of the state because of its central nature. The terrain of the city is hilly with average mean sea level height of $500 \mathrm{~m}$. The 
development of the town follows similar pattern of most south western traditional settlements with settlement characterized by old traditional core and high population density. Osogbo has a tropical wet and dry climate, with a lengthy wet season and relatively constant temperatures throughout the course of the year. The climate is tropical in Osogbo. The average annual temperature is $26.1{ }^{\circ} \mathrm{C}$ and it has an average rainfall of $1150 \mathrm{~mm}$ which start from April to late October or early November; though it eases off in July or August. The dry season lasts from December to March, which is the period of intense heat.

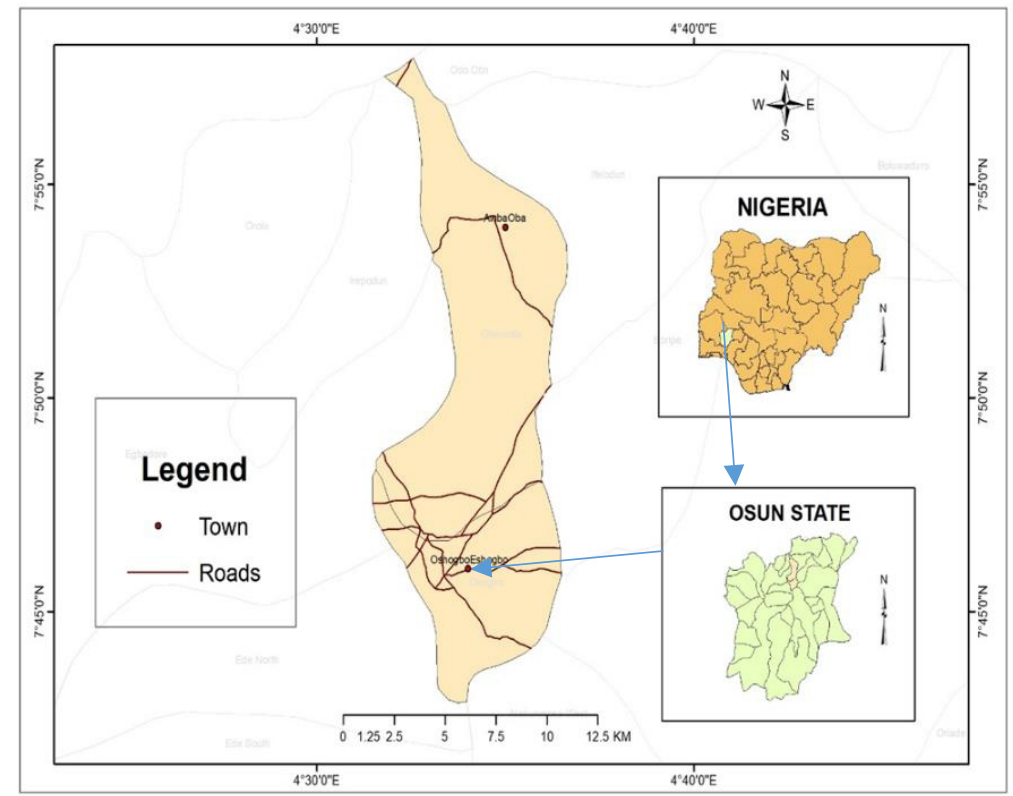

Figure 1.1: Study area

\section{Matherials And Methods}

\subsection{Materials}

The satellite data used was extracted from one scene (path/row: 184/ 55) of Landsat7 ETM and Landsatt8 OLI_TIRS Satellite images of 15th January 2000 and 15th November 2018 in UTM Projection Zone31, Datum WGS84. The bands selected for classification were 2, 4 and 7 (Weng, 2009 and Guha et al., 2017) while band 6 (Meng et al., 2017) was used to extract the land surface temperature (LST).The local boundary and Administrative shapefiles of Osogbo on the scale of 1:15,140,906 was obtained from Office of the Surveyor General of the Federation Abuja, Climatic data of Osogbo obtained from NIMET Lagos, Population data of Osogbo obtained from National Population Commission and information on the physical and socioeconomic variables and historical records of Osogbo was mostly obtained from web sources that are affiliated to the city. 
ERDAS Imagine 9.2, ArcGIS 10.4 and Microsoft office 2007 (word and Excel) were used. Erdas Imagine 9.2 was used for image processing and analysis. ArcGIS 10.4 was used for data preparation and map composition. Microsoft office (Word and Excel) was used for reporting and analysis.

\subsection{Methods}

The landsat spectral bands were stacked to produce a composite image of the study area for each year, 2000 and 2018. Thermal band 6 for Landsat 7 ETM and band 10 for Landsat 8 TIRS were used to extract the surface temperature for all the periods under consideration (Lunetta and Elvidge,1998). The areas of interest were clipped from the composite in Erdas Imagine 9.2. A land cover classification was carried out on the multi-year Landsat images by choosing Cultivation, Vegetation, Built-up and waterbody, as training classes for a supervised classification, using the Maximum Likelihood algorithm. Further classification correction and interpretation were carried out with the Google earth image of the study area. The error matrixes of the two land use and land cover maps were generated to assess the accuracy of the classification result.

The mono-window algorithm method was adopted to retrieve the LST from the imageries selected for this study, (Zhang et al., 2008). In the process, the NDVI was calculated first using the red and NIR bands 3 . The data output from this manipulation gave the NDVI image, which was used in calculating the Proportion of Vegetation which in turn was used to generate the emissivity. Consequently, the landsat thermal band 6 were used to retrieve LST over the study area for the two different years (2000 and 2018) based on the following steps:

The DN of the thermal bands of ETM+ were converted into spectral radiance values for each of the investigated years using the following equation -

Where;

$$
L_{\lambda}=\left(L M A X_{\lambda}-L M I N_{\lambda} / Q C A L_{M A X}-Q C A L_{M I N}\right) \times(D N-1)+L M I N_{\lambda}
$$

$L_{\lambda}=$ The spectral radiance at the sensor's aperture in $\mathrm{Wm}^{-2} \mathrm{sr}^{-1} \mu \mathrm{m}^{-1}$

$\mathrm{LMAX}_{\lambda}=$ Spectral radiance scaled to QCALMAX in $\mathrm{Wm}^{-2} \mathrm{sr}^{-1} \mu \mathrm{m}^{-1}$, available in the metadata.

$\mathrm{LMIN}_{\lambda}=$ Spectral radiance scaled to QCAL $\mathrm{QIN}_{\mathrm{N}}$ in $\mathrm{Wm}^{-2} \mathrm{sr}^{-1} \mu \mathrm{m}^{-1}$, available in the metadata.

QCAL $_{\text {MAX }}=$ Maximum quantized calibrated pixel value (corresponding to $\left.\mathrm{L}_{\mathrm{MAX}}\right)$ in $\mathrm{DN}=255$

QCAL $_{\text {MIN }}=$ Minimum quantized calibrated pixel value (corresponding to $\mathrm{L}_{\mathrm{MIN}}$ ) in $\mathrm{DN}=1$

$\mathrm{DN}=$ Digital Number of the Band 
For Landsat 8 with file data on Radiance Multiplier (M) and Radiance Add (B), the thermal infrared (TIR) band was converted into spectral radiance (L $\lambda$ ) using the equation -

Where;

$$
L_{\lambda}=M L Q_{C A L}+A L
$$

$L \lambda=$ The spectral radiance at the sensor's aperture in Wm-2 sr $-1 \mu \mathrm{m}-1$

$\mathrm{ML}=$ Band Specific Multiplicative Rescaling factor, gotten from the metadata of the image

$\mathrm{Q}_{\mathrm{CAL}}=$ Quantized and calibrated standard product pixel values (Digital Number)

$\mathrm{AL}=$ Band Specific Additive Rescaling factor, gotten from the metadata of the image.

Spectral radiance values for the bands were then converted to radiant surface temperature under an assumption of uniform emissivity using pre-launch calibration constants for the Landsat ETM+ sensor implemented into this equation;

$$
\mathrm{T}=\frac{\mathrm{K} 2}{\operatorname{in}(k 1 / L \lambda+1)}-273.15
$$

Where;

$\mathrm{T}=$ At-satellite brightness temperature in Degrees Celsius

$L \lambda=$ Spectral radiance in $\mathrm{Wm}-2 \mathrm{sr}-1 \mu \mathrm{m}-1$ (gotten from equations 1 and 2)

$\mathrm{K} 1=$ Band specific thermal conversion constant from the metadata

(K1_CONSTANT_BAND_X, $\mathrm{x}$ is the thermal band number)

$\mathrm{K} 2=$ Band specific thermal conversion constant from the metadata

(K2_CONSTANT_BAND_X, $\mathrm{x}$ is the thermal band number)

$-273.15=$ Constant for conversion from Kelvin to Degrees Celsius

In estimating LSE, Normalized Differential Vegetative Index (NDVI) was utilized for emissivity correction. The temperature values obtained using Equation (5) are referenced to a blackbody. Therefore, corrections for spectral emissivity $(\varepsilon)$ became necessary according to the nature of land cover. This equation was used;

Where,

$$
\mathrm{e}=\mathbf{0 . 0 0 4 P v}+0.986
$$

$\mathrm{e}=$ Land Surface Emissivity

0.004 and $0.986=$ Constants for emissivity estimation

$\mathrm{PV}=$ Proportion of vegetation given by the equation -

$$
P V=[(N D V I-N D V I m i n) /(N D V I m a x-N D V I m i n)]^{2}
$$

NDVI = Normalized Differential Vegetation Index for each of the years The index is defined by equation below -

$$
N D V I=(N I R-R E D) /(N I R+R E D)
$$


Where NIR and RED are the reflectance in the near-infrared and red portion

of the

electromagnetic spectrum respectively.

For LANDSAT 7 ETM+,

$$
N D V I=(B A N D 4-B A N D 3) /(B A N D 4+B A N D 3)
$$

Where Band 4 and Band 3 are the reflectance in the near-infrared and red portion of

Electromagnetic spectrum of the Thematic Mapper and Enhanced Thematic Mapper plus respectively.

For LANDSAT 8 OLI_TIRS

$$
N D V I=(B A N D 5-B A N D 4) /(B A N D 5+B A N D 4)
$$

Where Band 5 and Band 4 are the reflectance bands in the near-infrared and red portion of

Electromagnetic spectrum of Operation Land Imager (OLI) sensor of Landsat 8 respectively.

NDVImin $=$ Minimum value of NDVI for that year

NDVImax = Maximum value of NDVI for that year

Finally, having corrected the emissivity in equation (4), the LST was estimated using the equation;

Where.

$$
L S T=B T / 1+w \times B T P \times \ln (\mathcal{E})
$$

LST $=$ Land Surface Temperature in Degrees Celsius

$\mathrm{BT}=$ At-satellite brightness temperature

$\mathrm{W}=$ Wavelength of emitted radiance $(\mu \mathrm{m})$

$$
p=h \times c / s\left(1.438 \times 10^{-2}{ }_{\mathrm{m}} K\right)=14380
$$

$\mathrm{H}=$ Planck's constant $\left(6.626 \times 10-{ }^{34} J S\right), \mathrm{S}=$ Boltzmann constant $(1.38 \times$ $\left.10^{-23} \mathrm{~J} / \mathrm{K}\right), \mathrm{C}=$ Velocity of light $\left(2.998 \times 10^{8} \mathrm{~m} / \mathrm{s}\right), \mathrm{e}=\mathrm{LSE}$

Pearson's Product Moment Correlation analyses was carried out to determine the relationship between the rate of Temperature change and Human-induced Impacts in the study area. The Pearson's Product Moment Correlation Analysis is a statistical method that tests the measures of linear association between two quantitative variables, with the linear association going from +1 to -1 in decreasing order of strength. This equation is given as:

$$
r=\left(\Sigma x y-\frac{(\Sigma x)(\Sigma y)}{N}\right) /\left(\Sigma X^{2}-\left(\Sigma X^{2}\right) / N\right)\left(\Sigma Y-(\Sigma Y)^{2 / N}\right)
$$

Where $\mathrm{r}=$ Correlation Coefficient

$\mathrm{X}=$ Independent variable, which is the NDVI readings associated with each respective year. 
$\mathrm{Y}=$ Dependent variable, which is the land surface temperature readings associated with each respective year

$\mathrm{n}=$ Observations

To test the strength of the correlation, the coefficient of determination was used and it was calculated by:

$$
\mathrm{C} / \mathrm{D}=\mathbf{r}^{2}
$$

Where $\mathrm{C} / \mathrm{D}=$ Coefficient of determination.

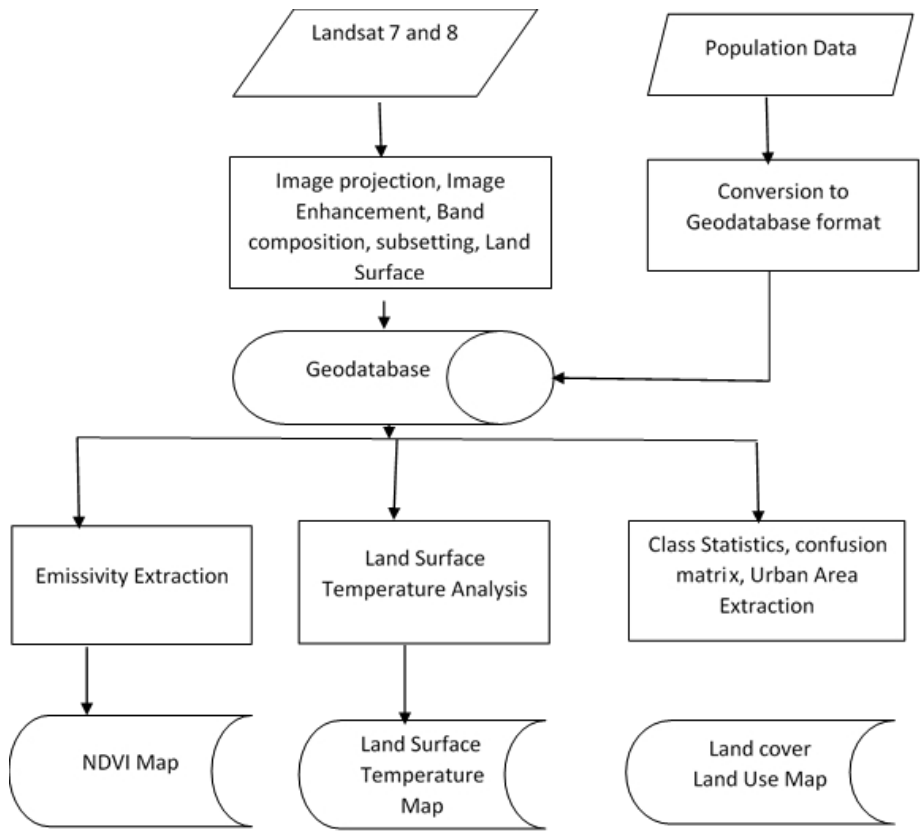

Figure 3.1: Methodology Flow Diagram

\section{Results And Discultion}

\subsection{Spatio-temporal Variability and Distribution of the Land Surface Temperature(LST)}

The land surface thermal property of the environment over the study area was examined using the land surface temperature maps for 2000 and 2018 (Figure 4.1 and 4.2). These land surface maps were the results gotten from the surface thermal analysis conducted in this study. From the LST maps (Figure 4.1 and 4.2 ) as depicted by their respective legend, the temperature ranges from $23-25^{\circ} \mathrm{C}$ (lowest temperature) and maximum temperature range of 31-33 ${ }^{\circ} \mathrm{C}$ with a mean value of $28.045 \mathrm{C}$ in 2000 and in the year 2018 , a negligible decrease in temperature was noted as the lowest temperature range was 21-24 ${ }^{\circ} \mathrm{C}$ and this could be attributed to the periods of data acquisition but the maximum temperature increased in 2018 at a range of $32-37^{\circ} \mathrm{C}$ with a mean value of $29.200{ }^{\circ} \mathrm{C}$ why the actual mean rate of change in land surface 
temperature between 2000 and 2018 was $1.155^{\circ} \mathrm{C}$ indicating overall increase in land surface temperature over the study periods. Figure 4.1 revealed the spatial distribution pattern of the land surface temperature over Osogbo city and it was clearly noted that the highest temperature value (pink tone) starting from $27-29^{\circ} \mathrm{C}$ and above was found at the core of the city of Osogbo in 2000 whereas the surrounding area was attributed to the lowest temperature. From Figure 4.2 (LST map for 2018), it could be noticed that the areas associated with highest temperature is no longer restricted towards the center of the city but has spread to other part of the study area where there has been a development.

Comparing figure 4.1 and 4.2 (LST maps) and figure 4.3 and 4.4 (LULC maps), it was noticed that the vegetative part of the study area is directly linked to area of lower temperature values while the area associated higher temperature values are built-up area, that is areas of human activities like deforestation, construction, cultivation, mining, logging, burning etc. and impervious surfaces.
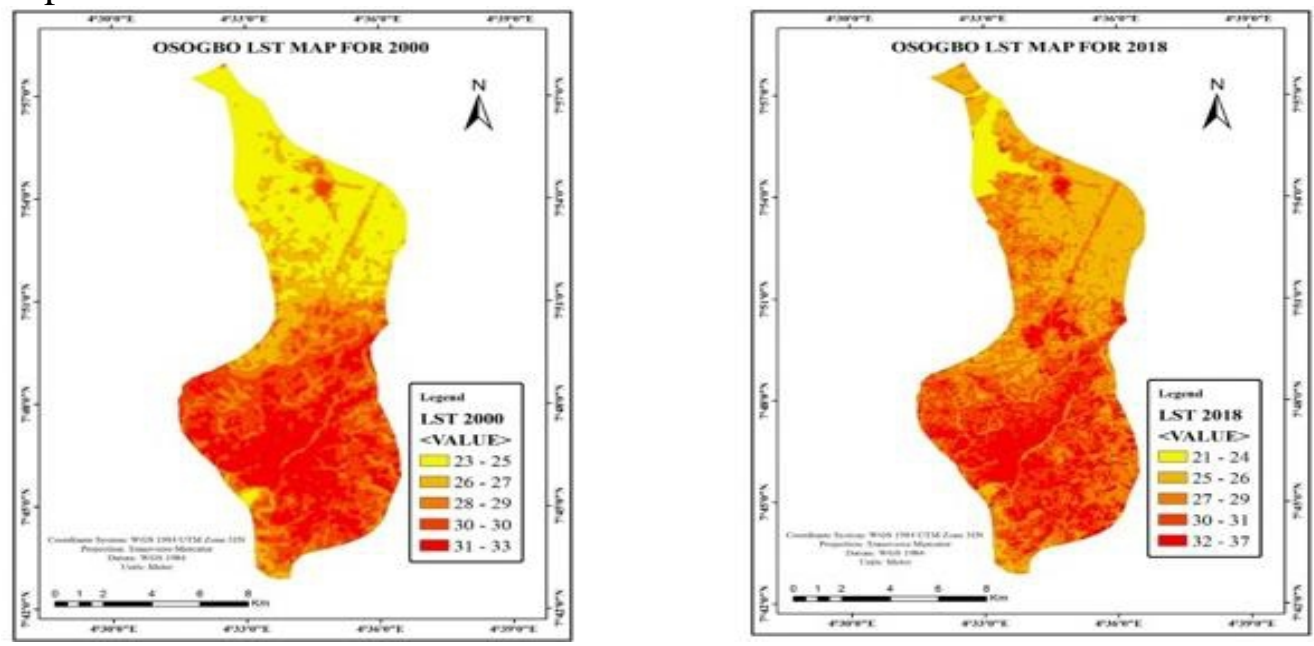

Fig.4.1:Map showing LST of Osogbo for 2000 Fig.4.2:Map showing LST of Osogbo for 2018

Table4.1: Land Surface Temperature Value Range over the years

\begin{tabular}{cccc}
\hline $\begin{array}{c}\text { Temperature } \\
\text { range } \\
\left({ }^{\circ} \mathrm{C}\right)\end{array}$ & $\begin{array}{c}\text { year } \\
2000\end{array}$ & $\begin{array}{c}\text { year } \\
2018\end{array}$ & $\begin{array}{c}\text { Increase between } \\
2000 \& 2018\end{array}$ \\
\hline & & & \\
\hline Lowest & 22.16 & 21.13 & -1.52 \\
Highest & 33.44 & 37.27 & 3.83 \\
MEAN & 28.045 & 29.2 & 1.155 \\
\hline
\end{tabular}

This result was in conformity with other previous studies by which has proven that land surface temperature will always be lesser over vegetation 
compare to exposed soil as a result of canopy intercepting the incoming solar radiation (short wave), reflect little and absorbs substantial amount which is converted to chemical energy that aid photosynthesis with the help of chlorophyll and loses it excess energy to evapotranspiration process (Fabeku, et al., 2018). Also most of the building materials used nowadays not only in the urban areas but in the suburbs has varying capacity of physical surface properties (albedo, thermal capacity and heat conductivity) that act as a major contributing factor to the environmental thermal increase.

It was also discovered from table 4.1 that between 2000 and 2018, the mean temperature was $28.045^{\circ} \mathrm{C}$ and $29.200^{\circ} \mathrm{C}$ respectively. These findings that built-up areas, cultivated land and others where there is development are associated with high land surface temperature whereas the parts with more of vegetation and waterbodies corresponds to low temperature was in line with the findings of (Jalan, and Sharma, 2014), which reported that highest land surface temperature corresponds to bare soil area, built-up areas and agricultural fallow land while water bodies record lowest LST followed by vegetation classes. (Weng, 2001) also reported related result where it was noted that commercial and industrial land exhibited the highest temperature followed by residential land. The lowest temperature was observed in forest areas followed by water bodies.

\subsection{Land use/ Land cover (LULC) Distribution and Change Detection Analysis Results}

Land use / Land cover geo-analysis over the study area was conducted in order to investigate not only the change that has taken place on the original vegetation cover but the nature and the magnitude of the land transformation due to human activities. Land use / land cover patterns for 2000 and 2018 were mapped using Landsat 7 ETM+ and Landsat 8 OLI_TIRS data respectively. The classes considered were Cultivation, Vegetation, Built up and waterbody. The resulting land use / land cover maps are shown in figure 4.3 and 4.4. The year 2000 was used as a base year for this study and the total area and percentage cover by each of the land use / land cover feature considered were presented on table 4.2 and figure 4.5 and 4.6.

According to the results on this table and figures the total built-up areas in Osogbo as at 2000 was only $27.3645 \mathrm{~km}^{2}$ accounting for $19 \%$ of the study area. However, in 2018, the total built-up areas increased to $59.3406 \mathrm{~km}^{2}$, representing $42 \%$ of the total land area that time. From this analysis, it is clear that there has been a considerable increase in built-up areas in between the two periods which could possibly mean only one thing, expansion in residential area coupled with more human induced activities over the region resulting from dynamic population growth. Vegetation cover over the study area as revealed on table 4.2 has decreased from $52.2711 \mathrm{~km}^{2}$ representing $37 \%$ in 
2000 to $36.1161 \mathrm{~km}^{2}$ representing $25 \%$ in 2018 . A decrease in the original vegetation was expected since a change induced by population growth has always being the major forcing factor in environmental transformation. There will always be an increase in population which calls for expansion in built-up, this expansion always results in constructions that facilitates deforestation, clearing and burning of bushes which results in tremendous decrease to flora population in many geographic locations of the world.

Cultivation on the other account for $57.4146 \mathrm{~km}^{2}$ representing $40 \%$ in 2000 and it occupied the largest class considered in 2000 but decreased to $41.589 \mathrm{~km}^{2}$ representing $29 \%$ in 2018 . This decreased in cultivation could be as a result of increase in built-up in the study area over the study periods which account for over $42 \%$ of the total classes considered with the largest land area cover of $59.3406 \mathrm{~km}^{2}$, in 2018 . Waterbody forms the hydrological component of the land cover type and it could serve as an indicator to average weather condition of any geographical environment. Longer period of increase in temperature or decrease in rainfall amount could cause it to reduce in size whereas improvement in rainfall amount will definitely leads to increase both surface under grand water availability. Table 4.2 and figure 4.5 and 4.6 shows that the waterbody over the study area increased marginally from $5.6421 \mathrm{~km}^{2}$ representing $4 \%$ in 2000 to $5.6466 \mathrm{~km}^{2}$ representing the same $4 \%$ in 2018 with increase of $0.00025 \mathrm{~km}^{2}$. This marginal increase in waterbody could be as a result of improvement in rainfall in 2018 compared to 2000 or as a result of built-up encroaching or interfering with water ways leading to diversion of water.

Table 4.2: Statistics Showing The Lulc Over The Study Peroids.

\begin{tabular}{llll}
\hline \multirow{2}{*}{ Land Use } & 2000 & 2018 & RATE OF CHANGE \\
& LULC(KM2) & LULC $(\mathrm{km} 2)$ & BETWEEN 2000-2018 \\
\hline Vegetation & 52.2711 & 36.1161 & -0.8975 \\
Cultivation & 57.4146 & 41.589 & -0.8792 \\
Water Body & 5.6421 & 5.6466 & 0.00025 \\
Builtup & 27.3645 & 59.3406 & 1.77645 \\
\hline
\end{tabular}



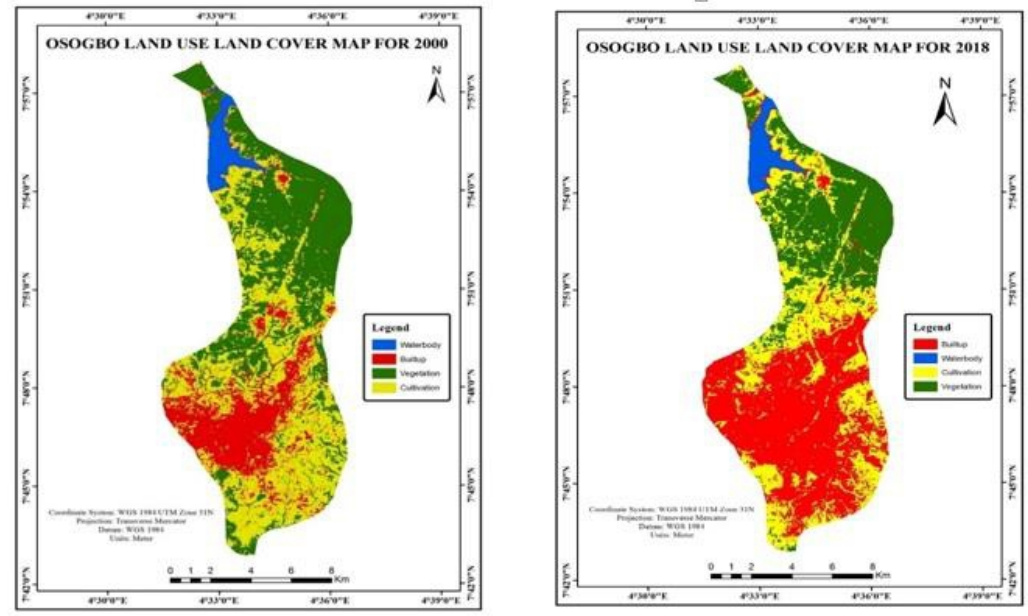

Fig.4.3 \& 4.4: Maps showing LULC of Osogbo for 2000 \& 2018
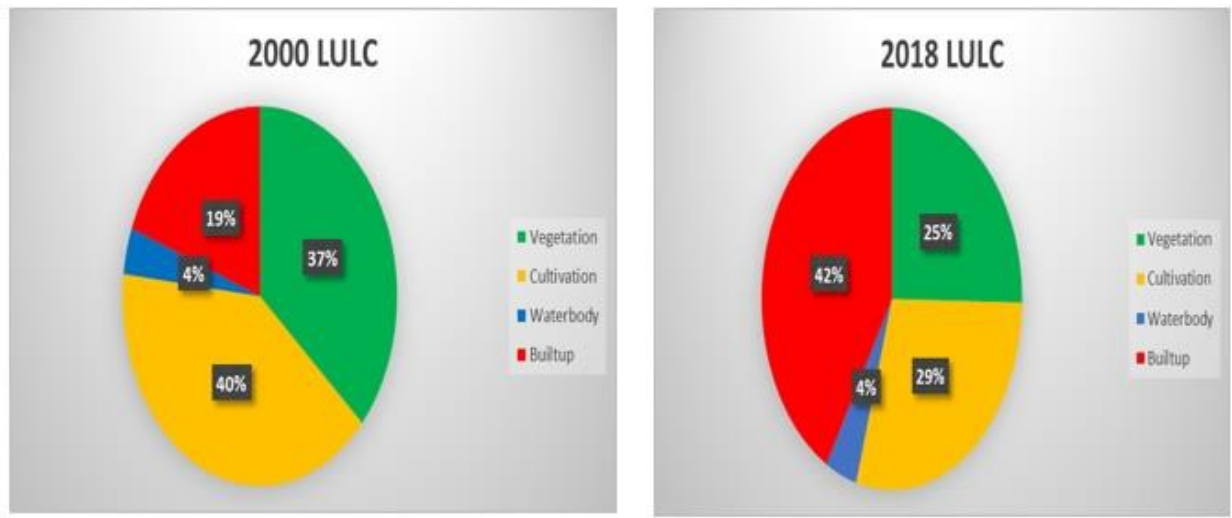

Fig.4.5 \& 4.6: Pie charts showing LULC Osogbo for 2000 and 2018
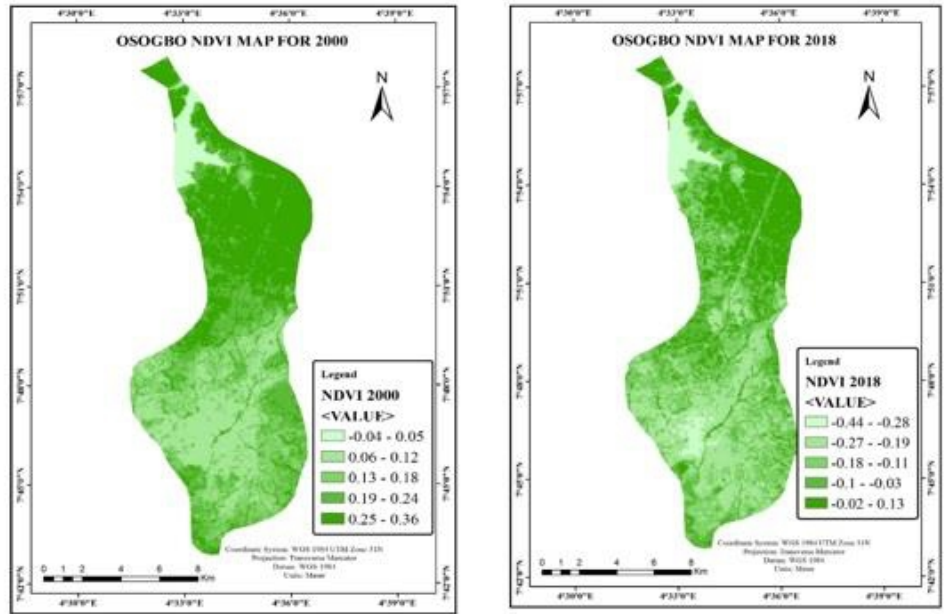

Fig.4.7 \& Fig.4.8: Maps showing NDVI of Osogbo for 2000 and 2018 
Table 4.3: Showing Correlation Matrix Values Between Lst And Ndvi

\begin{tabular}{lllll}
\hline & LST_2000 & LST_2018 & NDVI_2000 & NDVI_2018 \\
\hline LST_2000 & 1 & 0.8196738 & - & - \\
LST_2018 & - & 1 & - & - \\
NDVI_2000 & -0.544183 & -0.349720 & 1 & 0.848568987 \\
NDVI_2018 & -0.455506 & -0.485127 & - & 1 \\
\hline
\end{tabular}
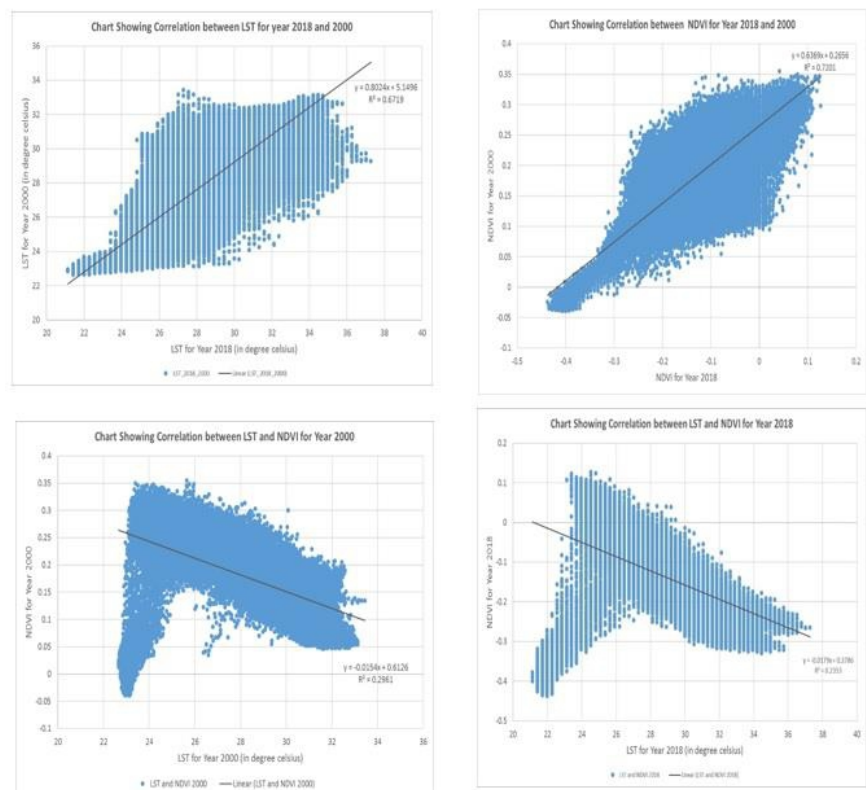

Fig. 4.9-4.12: Graphs showing relationship between LST \& NDVI of Osogbo for 2000 \& 2018

\subsubsection{Lst-Lulc Relationhip}

In other to investigate the kind of relationship that exist between land surface temperature and the land cover type over the study area, land cover type index features (LULC of 2018) were digitized and overlayed on the LST map (LST 2018), LULC map and LST map of Osogbo for 2018 were placed side by side to determine their association and the results were presented in figure 4.13 and 4.14.These results revealed that LST intensity are obvious where human and anthropogenic activities were significant (settlement areas) whereas areas with low temperature intensity were attributed to vegetation and waterbody areas. This result is in line with Aderoju et al.,2013), which reported that Urban Heat Island Effect in not always at the city but sometimes in the outskirt where a lot of developmental activities were going on towards the direction of urban expansion. These findings that built-up areas and others where there is development are associated with high land surface temperature whereas the parts with more of vegetation and waterbodies corresponds to low temperature was in line with the findings of (Jalan, and Sharma, 2014), which 
reported that highest land surface temperature corresponds to bare soil area, built-up areas and agricultural fallow land while water bodies record lowest LST followed by vegetation classes. (Weng, 2001) also reported related result where it was noted that commercial and industrial land exhibited the highest temperature followed by residential land. The lowest temperature was observed in forest areas followed by water bodies.

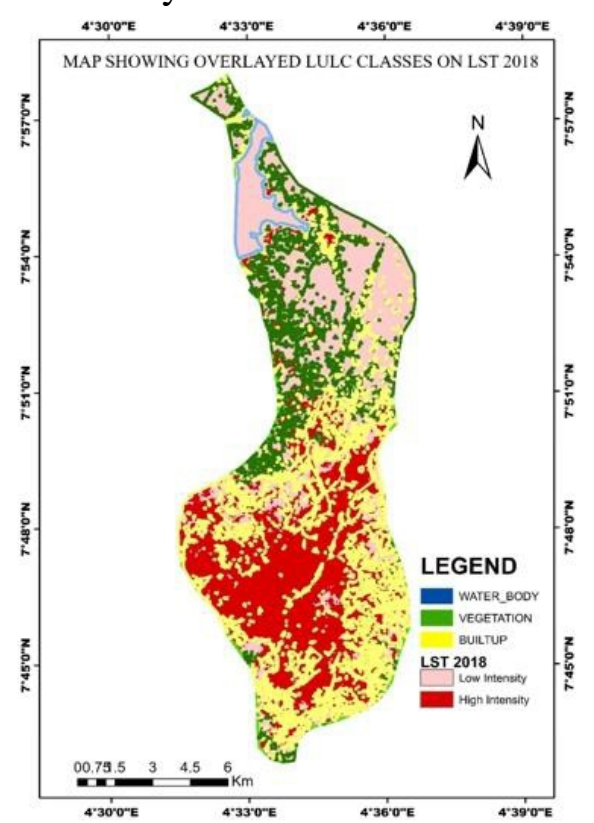

Fig. 4.13: Map showing the relationship between LULC classes and LST of Osogbo for 2018
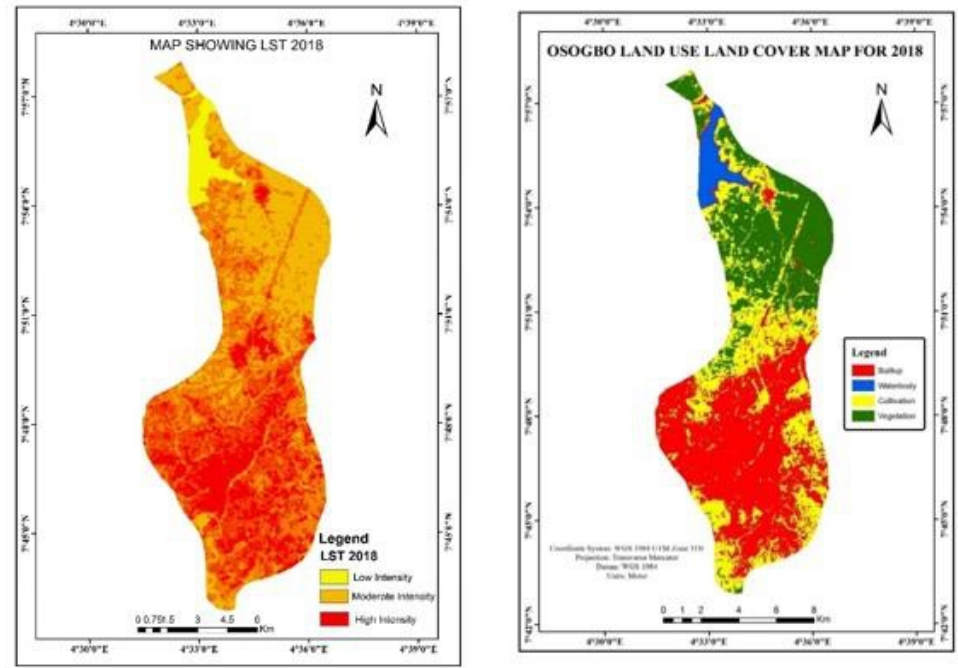

Fig.4.14: Maps showing association between LULC Index and LST of Osogbo for 2018 


\section{Conclusions}

1. This study has reported a continuous decrease in vegetation and cultivated land in Osogbo between 2000 and 2018 (from 37\% to 25\%) and $(40 \%$ to $9 \%)$ respectively and an increase in built-up within the same year (from $19 \%$ to $42 \%$ ) which could be attributed to anthropogenic activities such as roads, buildings, constructions, mining, deforestation etc. This change was found to be positively correlated to land surface temperature intensity over the region.

2. Continuous increase in land surface temperature and Urban Heat Island over Osogbo was also noted in this study and the LST distribution maps revealed that LST intensity are obvious where human activities are significant. And since the nature of land use / land cover patterns is capable of exerting influence on the nature of LST intensity, the way in which Osogbo develops over the coming decades will play a critical role in determining the characteristics of Osogbo's environmental temperature under climate change. It is expected that as the city expand further the magnitude of the land surface temperature would become stronger affecting the living conditions of the urban populace.

3. The correlation coefficient values of -0.54418 and -0.48513 in the respective years 2000 and 2018 observed between LST and NDVI shows that there exists an inverse relationship between LST and vegetation cover (NDVI) indicating that a decrease in NDVI led to increase in LST and this relationship helps find out the best solutions for urban environmental quality improvement and the planning strategies for Urban Heat Island reduction. These strategies are essential for the future of urban development as it may become necessary to apply these solutions to reduce the harmful impacts of human activities on the natural ecosystem.

\section{Recommendations}

The variations in land surface temperatures identified over the study periods suggest that urban growth is a major factor responsible for land transformation in the study area. The increase in rate of land surface temperature has its attendant effects on both the environment and the health of residents. Therefore, planting of trees or reforestation planning in and around Osogbo metropolis should be encouraged to minimize the increase in land surface temperatures of the town. City planning; location of the cities in a region, its layout and orientation, street network, density of built up area, types of buildings and green area should be carefully planned. Future research works should focus on integrating GIS and satellite remote sensing with high spectral, spatial and temporal resolution at the local scale to develop urban 
environmental monitoring. Moreover, research works should draw attention to urban land use modeling and techniques integrating socio-economic data and GIS tools to predicting future pattern of change. Focus should be given to the effect of urban growth and growing impervious surfaces, water pollution and other harmful human activities, etc.

\section{References:}

1. Adedotun, S. B., Ogundahunsi, D. S., and Oyeniyi, A. S. (2016). Assessment of road transport infrastructure in Osogbo, Osun State, Nigeria. WIT Transactions on the Built Environment, 164: 61 - 72.

2. Aderoju, O. M., Samakinwa, K and Ibrahim, I. (2013). An assessment of urban heat island in Akure using geospatial techniques. IOSR Journal of Environmental Science, Toxicology and Food Technology (IOSR-JESTFT), 45 (4): $24-34$.

3. Alkali, J. L. (2005). Planning sustainable urban growth in Nigeria: Challenges and strategies. In Proceedings of the Conference on Planning Sustainable Urban Growth and Sustainable Architecture, 2.

4. Argüeso, D., Evans, J. P., Pitman, A. J and Di Luca, A. (2015). Effects of city expansion on heat stress under climate change conditions. PLoS one, 10 (2): e0117066.

5. Auffhammer, M., Baylis, P., and Hausman, C. H. (2017). Climate change is projected to have severe impacts on the frequency and intensity of peak electricity demand across the United States. Proceedings of the National Academy of Sciences, 114 (8): 1886 - 1891.

6. Ayedun, C. A., Durodola, O. D. and Akinjare, O. A. (2011). Towards ensuring sustainable urban growth and development in Nigeria: challenges and strategies. Business Management Dynamics, 1 (2), 99 - 104.

7. Bowen, A., Cochrane, S and Fankhauser, S. (2012). Climate change, adaptation and growth. Climate Change, 113 (2): 95 - 106.

8. Chudnoky, A., Beb-Don, E and Saaroni, H. (2004). Diurnal thermal behaviour of selected urban objects using remote sensing measurements. Energy Build, 36:1063 - 74.

9. Cohen, B. (2006). Urbanization in developing countries: Current trends, future projections, and key challenges for sustainability. Technology in Society, 28 (1-2): 63 - 80.

10. Costello, A., Abbas, M., Allen, A., Ball, S., Bell, S., Bellamy, R., ... and Lee, M. (2009). Managing the health effects of climate change: lancet and University College London Institute for Global Health Commission. The Lancet, 373 (9676): 1693 -1733. 
11. Dahl, R. (2013). Cooling concepts: Alternatives to air conditioning for a warm world. Environmental Health Perspectives, 121 (1): 18-25.

12. Delay, M. E. (2018). Deforestation: facts, causes and effects. Lasell College Newton, Massachusetts.

13. Dousset, B., and Gourmelon, F. (2003). Satellite multi-sensor data analysis of urban surface temperatures and landcover. ISPRS Journal of Photogrammetry and Remote Sensing, 58 (1-2): 43 - 54.

14. Dousset, B., Gourmelon, F., Laaidi, K., Zeghnoun, A., Giraudet, E., Bretin, P., ... and Vandentorren, S. (2011). Satellite monitoring of summer heat waves in the Paris metropolitan area. International Journal of Climatology, 31 (2), 313 - 323.

15. Emeodilichi, H. Mba. (2018): Assessment of environmental impacts of deforestation in Enugu, Nigeria. Scientific and Academic Publishing, 8 (4): 207 - 215.

16. Fabeku, B. B., Balogun, I. A., Adegboyega, S. A. A., and Faleyimu, O. I. (2018). Spatio-temporal variability in land surface temperature and its relationship with vegetation types over Ibadan, south-western Nigeria. Atmospheric and Climate Sciences, 8 (3), 318 - 336.

17. Georgescu, M., Chow, W. T., Wang, Z. H., Brazel, A., Trapido-Lurie, B., Roth, M., and Benson-Lira, V. (2015). Prioritizing urban sustainability solutions: coordinated approaches must incorporate scale-dependent built environment induced effects. Environmental Research Letters, 10 (6), 061001.

18. Goudie, A. (1999). The human impact on the natural environment. MIT press, Cambridge, Massachusetts.

19. Guha, S., Govil, H. \& Mukherejee, S. (2017). Dynamic of analysis and ecological evaluation of urban heat islands in Raipur city India. Journal of Applied Remote Sensing, 11 (3), 36020.

20. International Panel on Climate Change. (2014). Climate Change 2014 Synthesis Report Summary for Policymakers.

21. Jalan, S., and Sharma, K. (2014). Spatio-temporal assessment of land use/land cover dynamics and urban heat island of Jaipur city using satellite data. The International Archives of Photogrammetry, Remote Sensing and Spatial Information Sciences, 40 (8): 767.

22. Kimuku, C. W., and Ngigi, M. M. (2017). Study of Urban heat island trends to aid in urban planning in Nakuru County-Kenya. Journal of Geographic Information System, 9 (3): 309 - 325.

23. Kershaw, T., Sanderson, M., Coley, D., \& Eames, M. (2010). Estimation of The Urban Heat Island for Uk Climate Change Projections. Building Services Engineering Research and Technology, 251-263. 
24. Le Hung, T. (2014). Studies of land surface temperature distribution using multispectral image Landsat. Vietnam Journal of Earth Sciences, 36 (1), 82 - 89.

25. Lundgren-Kownacki, K., Hornyanszky, E. D., Chu, T. A., Olsson, J. A., and Becker, P. (2018). Challenges of using air conditioning in an increasingly hot climate. International journal of biometeorology, 62 (3): $401-412$.

26. Lunetta, R. S., and Evidge C. D. (1998): Remote Sensing Change Detection. Michigan: An Arbor press, Chapter 7:12,5-16.

27. Meng, X., Cheng, J., and Liang, S. (2017). Estimating land surface temperature from feng yun-3c/mersi data using a new land surface emissivity scheme. Remote Sensing, 9 (12): 1247.

28. Mfon, P., Akintoye, O. A., and Ukata, S. U. (2014): Challenges of Deforestation in Nigeria and the Millennium Development Goals, International Journal of Environment and Bioenergy, 9 (2): 79-94.

29. Nnadi, C., Oladejo, J., Yennan, S., Ogunleye, A., Agbai, C., Bakare, L., .. \& Ronveaux, O. (2017). Large outbreak of Neisseria meningitidis serogroup C-Nigeria, December 2016-June 2017. MMWR. Morbidity and mortality weekly report, 66 (49): 1352.

30. Owen, T.W., Carlson, T.N. \& Gillies, R.R. (1998). An assessment of satellite remotely-sensed land cover parameters in quantitatively describing the climatic effect of urbanization. International Journal of Remote Sensing, 19, 1663-1681.

31. Quattrochi, D. A., and Luvall, J. C. (2014). Thermal infrared remote sensing for analysis of landscape ecological processes: current insights and trends. Scale Issues in Remote Sensing, 34 - 60.

32. Streutker, D.R., (2002): A remote sensing study of the urban heat island of Houston, Texas. International Journal of Remote Sensing, 23,2593-2608.

33. Treitz, P.M., Howard, P.J. \& Gong, P. (1992). Application of satellite and GIS technologies for landcover and land-use mapping at the ruralurban fringe: a case study. Journal of Photogrammetric Engineering and Remote Sensing, 58, 439-448.

34. Voogt, J. A., and Oke, T. R. (2003). Thermal remote sensing of urban climates. Remote sensing of environment, 86 (3): 370 - 384.

35. Weng, Q. (2001). A remote sensing? GIS evaluation of urban expansion and its impact on surface temperature in the Zhujiang Delta, China. International journal of remote sensing, 22 (10), 1999 -2014.

36. Weng, Q. (2009). Thermal infrared remote sensing for urban climate and environmental studies: Methods, applications, and trends. ISPRS Journal of Photogrammetry and Remote Sensing, 64 (4), 335 -344. 
37. Zhang, Z., Ji, M., Shu, J., Deng, Z., and Wu, Y. (2008). Surface urban heat island in Shanghai, China: Examining the relationship between land surface temperature and impervious surface fractions derived from Landsat ETM+ imagery. International Archives of the Photogrammetry, Remote Sensing and Spatial Information Sciences ISPRS Archives, 37: 601 - 606.

38. Zhou, L., Dickinson, R. E., Tian, Y., Fang, J., Li, Q., Kaufmann, R. K., $\ldots$ and Myneni, R. B. (2004). Evidence for a significant urbanization effect on climate in China. Proceedings of the National Academy of Sciences, 101 (26): 9540 - 9544. 